\title{
Visibilidad, alcance Editorial y crecimiento de la Revista Argentina de Cardioangiología Intervencionista (RACl) 2018/2019
}

\author{
Visibility and editorial scope of the Argentine Journal of Interventional \\ Cardioangiology (RACI) in the last two years
}

Revista Argentina de Cardioangiología Intervencionista 2019;10(4):0148-0149. https://doi.org/10.30567/RACI/201904/0148-0149

El año pasado publicamos [RACI 2018;9(4):194], con el empleo de las herramientas de Google Analytics, datos de la visibilidad y el alcance editorial de RACI.

En ese artículo se expresaba que, durante el período 1 de julio 2016 al 6 de diciembre del 2018, ingresaron a la página web de RACI 9224 usuarios (personas individuales no repetidas) que accedieron 12.854 veces a los contenidos, a razón de 1,4 acceso por usuario. Teniendo en cuenta el número de socios del CACI, esto significaba que el $93 \%$ de los que visitaban la revista eran "no miembros".

En el año 2017 entraron a la página web 3439 usuarios, que accedieron 4878 veces a sus materiales. El país de origen de los cinco principales usuarios fue durante el año 2017: Argentina en el 57,3\%, EE.UU. 12,5\%, México 8,4\%, España $3,1 \%$ y Canadá 3,0\%.

En esta oportunidad presentamos el mismo análisis, pero solo de los años 2018 y 2019, comparando también con lo visto en el 2017.

Utilizando la misma metodología de Google Analytics durante 1 de diciembre del 2017 a 1 de diciembre del 2018, ingresaron 4484 usuarios con 5804 sesiones abiertas es decir 1,29 sesiones por usuario. Desde el 2 de diciembre del 2018 hasta el 1 de diciembre del 2019, 5010 usuarios accedieron a RACI y abrieron 6632 sesiones, es decir, 1,32 sesiones por usuario, lo que indica un aumento del número de sesiones entre 2018 y 2019 del 14,3\%.

Si hacemos el comparativo de los años 2017, 2018 y 2019, hubo un incremento de visitas de usuarios anualizadas entre el 2017/18 del 23,4\% y entre el 2018/19 del 11,5\% (Figura 1).

El origen geográfico de los usuarios en el 2019 fue: Argentina 58,6\%, México 8\%, EE.UU. 6,6\%, España 4,5\%, Colombia 3,2\%, Perú 2,5\%, Chile 2,2\%, Ecuador 1,8\%, Brasil 1.4\% y Canadá 1,3\%. Y durante 2018, el origen geográfico de los usuarios había sido: Argentina 45\%, EE.UU. 20,7\%, México 6,9\%, España 3,4\%, Perú 1,8\%, Chile 1,4\%, Ecuador 2,1\%, Brasil 1,2\% y Canadá 0,2\% (Figura 2). En estos tres últimos años se mantiene que dentro de los 10 puntos geográficos que más visitan la revista hay 5 países que están fuera de la región de América del Sur.

La relación de número de usuarios y socios de CACI demuestra que el interés por RACI excede con mucho el número de afiliados a nuestra Sociedad y excede el límite de la Cardiología Intervencionista.

Si bien revistas de otras sociedades pueden tener seguramente un número mucho mayor de visitas, hay que considerar el número de afiliados en cada una de ellas y la periodicidad de aparición de las mismas, ya que en su mayoría son mensuales o bimensuales.

Este continuo crecimiento de la visibilidad de RACI, producto de la contribución editorial de cada uno de los autores

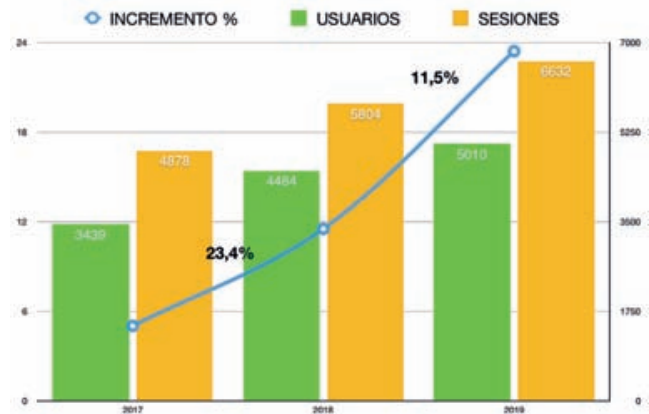

Figura 1. Crecimiento interanual del número de usuarios y de sesiones abiertas en el período 2017-2019.

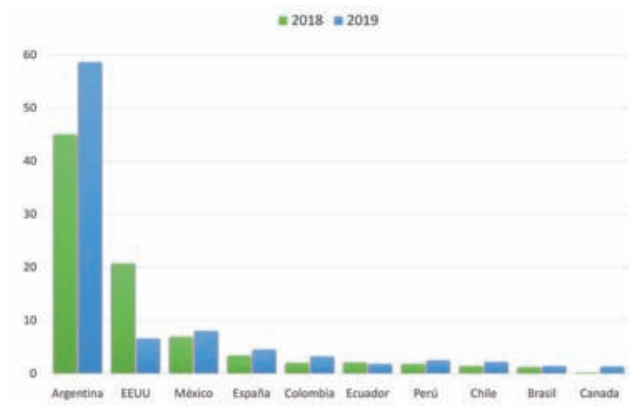

Figura 2. Alcance editorial y visibilidad por regiones geográficas. Comparación del número de usuarios según país de origen. 
de los trabajos en sus distintas versiones, nos compromete aún más a todos los miembros de nuestra Sociedad a continuar trabajando para aumentar la frecuencia editorial de la misma, así como una pronta inclusión en mayores buscadores europeos y de EE.UU.

A todos aquellos que nos acompañaron durante este año 2019, muchas gracias en nombre de todo el Comité Editorial y muchas gracias también a la Comisión Directiva del CACI, en especial a la figura de su Presidente Dr. Aníbal Damonte por el permanente compromiso y apoyo a RACI durante sus dos años de gestión.

Alfredo E. Rodríguez MD, PhD, FACC, FSCAI

Editor en Jefe Revista Argentina de Cardioangiología Intervencionista (RACI) 